\title{
Knowledge Sharing in Ontario Colleges: The Way to Sustainable Education
}

\author{
Rania Mohy EL Din Nafea ${ }^{1} \&$ Esra Kilicarslan Toplu ${ }^{1}$ \\ ${ }^{1}$ School of International Business and Management, Seneca College, Toronto, ON, Canada \\ Correspondence: Rania Mohy EL Din Nafea, Seneca College of Applied Arts and Technology, Toronto, ON, \\ Canada. Tel: 1-416-491-5050.
}

Received: February 10,2018 Accepted: February 25, 2018 Online Published: February 27, 2018

doi:10.5539/jms.v8n1p156 URL: https://doi.org/10.5539/jms.v8n1p156

\begin{abstract}
This paper puts forward several principles that the authors believe are essential for quality education in Canadian colleges. The relationship between establishing communities of practice, creating knowledge repositories, encouraging top management commitment to knowledge sharing and establishing a comprehensive reward system are examined in relation to innovation in education. Sustainable Development Goal (SDG) \#4 of the UN postulates quality education among its top initiatives.

The question that arises is how do we ensure that SDG \#4 is implemented in higher education institutions? Accordingly, data was collected through observation of faculty and staff from the 2017 Ontario Colleges strike. Although a strong corporate culture exists in Ontario colleges, the system continues to struggle with explicit top management principles that support knowledge sharing across different disciplines. Inter and intra departmental forums including students are non-existent. Knowledge repositories, that staff, faculty and students can tap into are lacking. A greater conversation with stakeholders is imperative to weave all the threads of organizational behavior practices together to nurture future global citizens. Only then can we achieve sustainable quality education.
\end{abstract}

Keywords: innovation, education, knowledge sharing, communities of practice, reward system, top management, sustainability

\section{Introduction}

Education is considered a vital prerequisite and a foundation to reform in any country. It is one of the most powerful and proven vehicles for achieving all the Sustainable Development Goals (SDGs) of UN Global Compact. United Nations members also positioned education at the heart of the strategy to promote sustainable development (Annan-Diab \& Molinari, 2017).

Besides this, it is known that innovation is crucial for the new world of sustainability, and sustainability depends on fundamental, disruptive and system-wide innovation. As a report issued by the World Business Council for Sustainable Development puts out, "Innovation is at the core of creating a sustainable human society. As a society, we will not succeed in creating a sustainable world if we focus merely on doing more efficiently what we currently do." (Gobble, 2012)

Over the past two decades there have been many case studies that point out the significance of creating a knowledge-sharing environment in the workplace and its impact on sustainable innovation. Fortune 500 companies like GE, Xerox and Google have thrived on creating an organizational culture that is conducive to knowledge transfer between employees. Not only did that entail creating information repositories and forming communities of practice, but also ensuring that top management support and job autonomy were part of the equation.

Ontario Colleges in Canada have been calling for a reform for some time now as evidenced by the five-week strike that was called for by the union in October 2017. Some of the major issues on the table included remuneration, job autonomy and academic freedom. Faculty felt they were not treated on an equal footing to their university counterparts in terms of pay, and moreover were not always permitted to deliver their courses in the manner they deemed fit. After some analysis of this situation and careful observation of faculty and staff from different Ontario Colleges and across different disciplines, the authors deduced that the Ontario College 
system requires innovation, but how could that be reached when they lack knowledge sharing?

One of the definitions of innovation is proposed by Greenhalgh, Robert, Macfarlane, Bate, \& Kyriakidou (2004) who define innovation as "a novel set of behaviors, routines and ways of working, which are directed at improving outcomes, administrative efficiency, cost-effectiveness, or the user experience, and which are implemented by means of planned and coordinated action."

Osbourne (1998) spanned decades of research and studied various definitions of innovation and further specified four viable aspects of innovation which are:

- "Innovation represents newness.

- It is not the same thing as invention. Invention is about discovery of new ideas or approaches; innovation is about their application.

- It is both a process and an outcome.

- It involves discontinuous change."

Successful and sustainable innovation in today's world is essential in order to improve our communities. What can be more important than improving the caliber of Canadian College graduates through a thorough reform of the existing system?

While innovation has been of interest to researchers for a long time, interest in the sustainability of innovation has been more recent. As well, greater attention has more recently shifted towards examining the complexity of innovation and its development-implementation and sustainability in the organizational context. Innovative solutions in today's world tend to be multi-partner, multi-stakeholder and multilayered. Higher education institutions are one of the main partners and stakeholders to the innovation process in any country since they are suppliers of the graduates that drive the economy.

Higher education institutes have to create responsible leaders, who will work towards building a more secure and sustainable future. They also play a critical role in knowledge transfer through partnering with companies and other organizations. Besides supporting learning by their teaching and training programs, they also support innovation, and social and cultural businesses (Fullwood, Rowley, \& Delbridge, 2013).

Studies show that knowledge transfer is a key element in the adoption of innovation. It is imperative to transfer new knowledge derived from research to those who need to know and who can help implement and sustain innovation. As Husseini \& Elbeltagi (2015) stated; because the world becomes more and more competitive, knowledge management and sharing is being accepted the most significant source for competitive advantage and the key to enhance innovation. Likewise as Llopis \& Foss (2016) quoted; knowledge sharing has been positively related to the formation of new products and services (Zhou \& Li, 2012), the transfer of best organizational practices (Pallotti, Tubaro, \& Lomi, 2015) and the development of competitive advantage (Llopis \& Foss, 2016). That is why knowledge sharing in higher education institutions is crucial.

Knowledge sharing is defined as an organization's employees' ability to transfer experiences, professional knowledge, values, contextual information and observations, targeting at creating institutional structures for the assessment and inclusion of new experiences and information (Kim \& Lee, 2005). According to the authors, knowledge sharing is not a systems' action, instead it is based on peoples' actions and their propensity to share their experiences and tacit information with one another.

According to Yi (2009), knowledge sharing behavior is "a set of individual behaviors involving sharing one's work-related knowledge and expertise with other members within one's organization, which can contribute to the ultimate effectiveness of the organization."

As Reyes (2014) quoted; Allee (1997) found that the fact of sharing knowledge is necessary for sustainability and organizational competitiveness. According to the author, knowledge is sent from a sender to a receiver, and the wider the content of the knowledge, the bigger the final product value will be, in addition it will be easier to duplicate.

As Skaik \& Othman (2014) stated; higher education institutions are knowledge-intensive environments, and are responsible for creating, managing, and circulating knowledge in society. They have to equip people with the best education in order to serve their societies and lift up the prosperity of mankind. Meanwhile, Sharma (2010) adds that higher education institutions need to promote knowledge sharing among their academics, staff, and students to ensure success, achieve their goals, and have constant performance improvements.

Sohail \& Daud (2009) stated that knowledge sharing is crucial in higher education institutions, while Cheng, Ho, 
\& Lau (2009) agreed that higher education institutions are where knowledge creation, management, sharing, and utilization is implanted. According to Cheng et al. (2009), knowledge sharing in these institutions could be more impactful than that created by business organizations. Therefore, one can conclude that higher education institutions are pillars of knowledge in any society.

Although, there are research studies about knowledge management and knowledge sharing in business organizations, and there is growing interest in knowledge management in public sector organizations, research into knowledge management in higher education institutions is very limited (Fullwood et al., 2013).

Much of the research that has been conducted on knowledge management and higher education institutions focuses on the ways in which they differ from other working environments, and the consequences for how knowledge might be managed and shared. There has, however, been little empirical research specifically into knowledge sharing in higher education institutions, partly due to the huge number of employees and the varying nature of work that colleges employ. Some concerns might include if knowledge sharing should be measured from the different stakeholders viewpoint versus that of the faculty. This has made it difficult to apply the same knowledge sharing questionnaires or validation techniques that would be applied in an industrial setting (Yi, 2009).

The hypotheses put forward by the researchers include:

H1: The organizational culture in Ontario colleges is not conducive to knowledge sharing.

H2: There is a lack of top management support and initiatives to encourage knowledge sharing.

H3: There is a lack of knowledge repositories in Ontario colleges to retain the tacit knowledge of professors and staff.

\section{Method}

As such, observation is the basis of data collection in this research. The strike has provided the researchers with a wealth of raw data from personal conversations and discussions. Going forward, this data should be supported with formal interviews and surveys, allowing for a full triangulation technique. Since Daft (1980) states that knowledge is one of the complex, intangible, emotional dimensions of organizations and cannot be handled through the fine filter of linear statistics, the researchers have decided to present their findings until further techniques are applied.

\section{Results and Discussion}

With regards to hypothesis H1, the hypothesis has been refuted. Ontario colleges do have a strong organizational culture, evidenced by their strong identities, working practices and role designs. Each of the Ontario colleges has a competitive edge, whereby schools have been able to brand themselves distinctly from one another. For example George Brown College is known for its culinary program, while Seneca College is known for its Business school. Students, faculty and staff all identify strongly with their respective colleges and have a feeling of pride and belonging.

Working practices differ from one college to another. While some colleges follow a more rigorous and procedure-based system, others have chosen to create an informal working culture. Regardless of the culture built inside the colleges, it seems that both faculty and staff have adjusted well to the systems. As such, job roles are well defined within those systems, although some staff members did complain of taking on additional work due to understaffing issues. Culture is an ecosystem; the elements of a culture interact with and reinforce each other (McGregor \& Doshi, 2015). A strong culture provides organizations with a competitive edge that leads to superior performance, customer satisfaction and long-term sustainability.

With that being said, there seems to be a gap between corporate culture and top management initiatives and directives. There are no formal efforts undertaken by the college administration to promote knowledge transfer; departments are left to decide whether or not they share information, when and with whom. Without a unified policy to guide each college, sustainable long-term knowledge sharing will not be possible. If each department decides its own policy, colleges will fall into the trap of duplication, which not only wastes time and money but also leads to re-inventing the wheel. Regular monthly meetings should be arranged between department deans to discuss means of collaboration, updates and sharing opportunities. Faculty should be allowed to share their expertise across different departments. A business professor should teach in the business, aviation and culinary programs. That will result in well-rounded professors who are exposed to different programs and teaching methods, which adds to their skill set and experience. On the other hand, students are exposed to a myriad of professors, each with their own unique experience and teaching style. 
One of the main issues uncovered through conversations with other faculty members was the reward system in Ontario colleges. Staff/faculty are not encouraged/rewarded for external collaboration outside their respective schools. Rewards should be tied to a $360^{\circ}$ performance management system, where faculty members should be assessed on their teaching, peer and student interaction, research efforts in academia or industry as well as additional initiatives undertaken including knowledge transfer. This may include sharing material through forums with other colleges to work on a unified methodology such as research, or coordinating efforts with other departments within the same college to enhance student experience. The focus of both inter and intra departmental knowledge transfer is to create a competitive advantage within colleges that cannot be replicated. If colleges are able to sustain this competitive advantage and partner with all the relevant stakeholders in the community to create meaningful knowledge, this will lead to innovation. As such hypothesis $\mathrm{H} 2$ has been accepted.

Innovation is a continuous process of change that strives towards more efficient and effective practices. Having said that, information sharing, retention, dissemination and analysis are crucial. This can only be done through the initiation of a repository of knowledge where the organization's tacit and explicit information can be retained. Observation has uncovered that there is a lack of a formal repository of course information where professors can refer to get previous course information, documents, exams, assessments etc. There should be an electronic system where minutes of meetings, announcements, college activities and the like are maintained. This concept is not only linked to sustainability through carbon footprint reduction, but also leads to increased transparency within the college system. The only way to ensure that staff and faculty are continuously developed stems from organizing regular open forums for faculty and students to interact across different departments. These initiatives can be organized in the form of seminars where faculty can share their ideas, papers, concerns and college activities with student input. This inter-disciplinary collaboration will motivate students to voice their concerns and ideas leading to more active global citizens - a prerequisite to sustainable education. Accordingly, hypothesis $\mathrm{H} 3$ has been accepted.

\section{Conclusion}

To conclude one would say that sustainable innovation in education is a complete cycle and a continuous process that starts with critical organizational behavior efforts including knowledge sharing practices, top management initiatives and a dynamic reward system to drive innovation in education. It is interesting to see that SDG 4 focusing on education has been placed amongst the top five priorities by the United Nations. This is due to a general awareness that nations cannot progress without a complete overhaul or advancement of their educational systems with the help of qualified educators. Research results show that educators in Ontario are unmotivated and underpaid, which will lead to a decline in productivity and quality in the future. Administrators and Ministry officials should ask themselves the question "is this the environment we want our students to thrive in?"

Knowledge transfer initiatives need to be put into practice and supported by top management. Repositories of developed courses, learning materials and papers need to be shared between faculty members. Not only will this save time and effort, but also increase productivity. Faculty needs to be part of student recruitment initiatives since they are the ones aware of the quality of students in the classroom. Continuous involvement with industry representatives is imperative to ensure that educators are informed of current trends and are given the opportunity to create networking contacts that will benefit students in the future.

Educators should spend their time engaging students in activities that will enhance their critical thinking skills, encourage a more entrepreneurial mindset and enrich their employability skills. Time spent re-inventing the wheel in daily activities is simply an opportunity cost in the wrong direction and will not lead to sustainable education practices required in today's global and digital economy. We need to stimulate our students and faculty to share and think... As Albert Einstein said: "Education is not the learning of facts, but the training of the mind to think."

\section{References}

Al-Husseini, S., \& Elbeltagi, I. (2015). Knowledge sharing practices as a basis of product innovation: A case of higher education in Iraq. International Journal of Social Science and Humanity, 5(2), http://dx.doi.org/10.7763/IJSSH.2015.V5.449

Annan-Diab, F., \& Molinari, C. (2017). Interdisciplinarity: Practical approach to advancing education for sustainability and for the Sustainable Development Goals. The International Journal of Management Education, 15(2), Part B, 73-83. https://doi.org/10.1016/j.ijme.2017.03.006

Cheng, M. Y., Ho, J., \& Lau, P. M. (2009). Knowledge sharing in academic institutions: A study of Multimedia 
University Malaysia. Electronic Journal of Knowledge Management, 7(3), 313-324. Retrieved from www.ejkm.com/issue/download.html?idArticle=184

Daft, R. L. (1980). The evolution of organization analysis in ASQ, 1959-1979. Administrative Science Quarterly, 25, 623-636. Retrieved from http://www.jstor.org/stable/2392284

Fullwood, R., Rowley, J., \& Delbridge, R. (2013). Knowledge sharing amongst academics in UK Universities. Journal of Knowledge Management, 17(1), 123-136. http://dx.doi.org/10.1108/13673271311300831

Gobble, M. A. M. (2012). Innovation and sustainability. Research-Technology Management, 64-66. http://dx.doi.org/10.5437/08956308X5505005

Greenhalgh, T., Robert, G., Macfarlane, F., Bate, P., \& Kyriakidou, O. (2004). Diffusion of innovations in service organizations: Systemaic review and recommendations. The Milbank Quarterly, 82, 581-629. Retrieved from https://www.ncbi.nlm.nih.gov/pubmed/15595944

Kim, S., \& Lee, H. (2005). Employee knowledge sharing capabilities in public and private organizations: Does organizational context matter? Proceedings on the 38th Hawaii International Conference on System Sciences. http://dx.doi.org/10.1109/HICSS.2005.234

Llopis, O., \& Foss, N. J. (2016). Understanding the climate knowledge sharing relation: The moderating roles of intrinsic motivation and job autonomy, European Management Journal, 34, 135-144, http://dx.doi.org/10.1016/j.emj.2015.11.009

McGregor, L., \& Doshi, N. (2015). How company culture shapes employee motivation. Harvard Business Review. Retrieved from https://hbr.org/2015/11/how-company-culture-shapes-employee-motivation

Osborne, S. P. (1998). Organizational structure and innovation in U.K. Voluntary Social Welfare Organizations: Applying the Aston Measures. International Journal of Voluntary and Nonprofit Organizations, 9, 345-362. Retrieved from https://link.springer.com/article/10.1023/A:1022145831027

Pallotti, F., Tubaro, P., \& Lomi, A. (2015). How far do network effects spill over? Evidence from an empirical study of performance differentials in interorganizational networks. European Management Review. Retrieved from http://onlinelibrary.wiley.com/doi/10.1111/emre.12052/full

Reyes, M. M. V., \& Zapata, D. I. C. (2014). Relation between organizational climate and its dimensions and knowledge-sharing behavior among knowledge workers. International Journal of Psychology Research, $7(2), 64-75$.

Sharma, A. (2010). Enabling knowledge management of organizational memory for groups through shared topic maps (Unpublished master's thesis). Iowa State University. Retrieved from http://lib.dr.iastate.edu/etd/11185

Skaik, H. A., \& Othman, R. (2014). Investigating academics' knowledge sharing behaviour in United Arab $\begin{array}{lllll}\text { Emirates. Journal of Business and } & \text { Economics, } & 5(1), & 1-19 .\end{array}$ http://dx.doi.org/10.15341/jbe(2155-7950)/01.06.2015/016

Sohail, S., \& Daud, S. (2009). Knowledge sharing in higher education institutions: Perspectives from Malaysia. The Journal of Information and Knowledge Management Systems, 39(2), 125-142. http://dx.doi.org/10.1108/03055720910988841

Yi, J. (2009). A measure of knowledge sharing behavior: Scale development and validation. Knowledge Management Research \& Practice, 7, 65-81. http://dx.doi.org/10.1057/kmrp.2008.36

Zhou, K. Z., \& Li, C. B. (2012). How knowledge affects radical innovation: knowledge base, market knowledge acquisition, and internal knowledge sharing. Strategic Management Journal, 33(9), 1090-1102. http://dx.doi.org/10.1002/smj.1959

\section{Copyrights}

Copyright for this article is retained by the author(s), with first publication rights granted to the journal.

This is an open-access article distributed under the terms and conditions of the Creative Commons Attribution license (http://creativecommons.org/licenses/by/4.0/). 